\title{
NÔ - O NASCIMENTO DO TEATRO JAPONÊS
}

\author{
Sakae Murakami Giroux
}

Antes de entrarmos no tema proposto, é necessário lembrar que o teatro, hoje conhecido com o nome de nô, era, nos tempos antigos, denominado sarugaku.

$\mathrm{Na}$ verdade, é apenas nos meados da época Muromachi, por volta do século $\mathrm{XV}$, que o termo nô passa a ser utilizado para designar a representação de sarugaku. Aliás, foi também no decorrer desse mesmo século que Zeami, o grande dramaturgo e teorizador do nô, concluiu os preceitos de aperfeiçoamento da arte de sarugaku, iniciados por seu pai Kan'ami. Foi portanto, na época em que a referida arte atinge um nível considerável de representação que ela passa também a ser denominada nô.

Por outro lado, o termo nô era também utilizado, nessa época, para designar uma peça, uma representação ou mesmo uma interpretação de sarugaku e de dengaku - este último, arte que muito influenciou Zeami na sua procura do Belo. Dizia-se, portanto, "nô de sarugaku" ou "nô de dengaku" para indicar uma representação de sarugaku ou uma peça de dengaku, respectivamente.

Enfim, o que queremos aqui destacar é que o termo nô utilizado para designar o gênero teatral clássico da Idade Média Japonesa, coexistiu, ainda por um longo tempo, com o termo sarugaku, provavelmente até os meados do século XIX. Essa ressalva é importante para a nossa exposição, na medida em que procuraremos verificar o processo histórico pelo qual passou o sarugaku, desde a sua origem até a época de Zeami, ou melhor, os fatos sociais e históricos que contribuíram para o desenvolvimento do sarugaku até atingir um determinado nível de representação denominado nô. trabalho.

Isto posto, passaremos a esclarecer e justificar o título dado a este

Se voltarmos a nossa atenção ao Japão da época antiga, aquele do século VIII ao XII, deparamos com o bugaku que tinha uma posição de destaque entre todas as outras artes de representação, privilegiado pelo apoio 
e proteção da aristocracia. Mas o bugaku, embora tenha recebido uma certa coloração japonesa no tempo de sua implantação neste país, por volta do século XI, conservava - e ainda conserva - as fortes características do scu país de origem, a China, da época da dinastia dos Tang (618-907) e também as características dos três reinos da Coréia, por onde passou esta arte antes de chegar ao Japão. O sarugaku, ao contrário, mesmo tendo suas origens na China dos Tang, apresenta toda a sua evolução no Japão, atingindo um grau de aperfeiçoamento artístico elevado, por meio dos trabalhos de dois grandes artistas: Kan'ami e Zeami.

Por outro lado, a relação entre a dança e a música que constituíam os elementos fundamentais do bugaku (aliás, comuns a todas as artes de representação do Oriente antigo) era diferente daquela que observamos no sarugaku.

No bugaku, a música, denominada gagaku, existia não só enquanto acompanhamento da dança, mas também, de uma forma independente. A aristocracia da época aprendia, para se cultivar, os instrumentos de corda e de sopro, executando as músicas de bugaku. No sarugaku, a música, ou melhor, a orquestração auxiliava a dança e o canto, desempenhando um papel fundamental enquanto laço de união entre os elementos desta arte.

A dança, por sua vez, constituía um elemento de base tanto do bugaku quanto do sarugaku, com uma diferença substancial de funções nestas duas representações. A dança do bugaku é uma simples dança, em que as figuras são extremamente simplificadas e formalizadas, sem que seja possível perceber nelas qualquer significado. Em contrapartida, a dança do sarugaku a que hoje chamamos de dança do nô, é igualmente formalizada, sendo, entretanto, as suas figuras, resultados de um estudo e de uma prática aprofundados da mímica. Tais trabalhos objetivavam atingir o nível superior da arte, isto é, o nivel de yûgen - o nível de uma representação elegante e cheia de charme. Desta forma, de uma dança simples do bugaku passou a uma dança fundamentada na mímica, a partir da qual, portanto, poderá ser desenvolvido um significado de interpretação. Talvez possamos, pela primeira vez na história das artes de representação japonesa, dar o nome de "teatro" para qualificar essa aliança da dança com a mímica, do canto com o diálogo onde a música serve de elo, esse corpo único que hoje chamamos de nô.

Qual foi, então, o processo vivido pelo sarugaku para atingir esse estágio de representação?

Se procurarmos a origem do sarugaku, ela nos conduzirá ao sangaku que veio da China dos Tang para o Japão, por volta do século VIII-XIX. Ali, em contato com as outras artes que já existiam no país como o dengaku, danças agrestes, a representação de jushi (danças com a finalidade de exorcizar os maus espíritos) ou de ennen (representações didáticas realizadas nos 
templos e monasteiros), o sangaku vai se enriquecendo e se aperfeiçoando. O sangaku, desde a sua formação na China, possuía diversos elementos das artes populares: era uma arte aberta, pronta a coexistir harmoniosamente com as outras e a se desenvolver livremente.

$\mathrm{Na}$ época da sua implantação no Japão, o sangaku tinha como ponto alto de seu espetáculo as acrobacias e as mágicas. Mas continha também uma espécie de mímica improvisada, bastante primária, com objetivos cômicos. Gradativamente, essa improvisação vai se impondo aos outros elementos do espetáculo a ponto de, por volta do século IX-X, passar a ser a sua atração principal. E a partir desse período que o sangaku, cujo ideograma significava "divertimentos diversos", passa a ser denominado sarugaku, "arte dos macacos"

Assim, à medida que as acrobacias e as mágicas, que antes predominavam no sangaku, vão sendo relegados a segundo plano, a mímica vai se firmando, tendo o seu conteúdo constantemente renovado através da imitação dos aspectos da vida cotidiana da época, fato que vai permitir ao sarugaku conservar a sua imagem sempre jovem e atraente.

Há, por exemplo, um documento denominado Shin sarugakki, "Notas sobre novos sarugaku", dos meados do século XI, de autoria de Fujiwara no Akihira (?-1066), onde se encontram alistadas as peças de sarugaku que o autor mais apreciava no curso de seus dez anos de espectador assíduo desta arte. Ora, na medida em que essas peças começam a ter título, percebe-se que as mímicas, no início simplesmente executadas por inspirações do momento, deixam de ser improvisadas e passam a ser previamente estabelecidas.

Assim, os primeiros botões do nô surgem já no fim da época antiga, por volta do século XI-XII. Todavia, para desabrocharem, enquanto arte de um corpo uno, é necessário esperar o final do século XIII, para os inícios do século XIV

Veremos, a seguir, quais foram os fatores sociais e políticos que privilegiaram o nascimento dessa fusão harmoniosa de elementos de representação, a que damos o nome de teatro.

Sem dúvida alguma, a aparição dos atores profissionais de sarugaku, assim como a organização desses atores em companhias teatrais em torno de importantes templos e monasteiros e, posteriormente, a sua ligação à classe guerreira, representaram a consolidação de um terreno propício para o surgimento do teatro $n \hat{o}$.

Julga-se que o sangaku, na época da sua implantação no Japão, ocupava um certo espaço nos templos e monasteiros, assim como na corte. A propósito, havia na corte uma escola chamada sangakko, onde os artistas vinham se formar. 
Por volta do século XI, quando a mímica passava a predominar nesta arte, o sangaku, já denominado sarugaku, era representado pelos funcionários da corte, após o kagura - representações xintoístas - por ocasião das festas de mudança das estações e das corridas de cavalo. O sarugaku fazia, assim, parte das artes de divertimento preferidas pela aristocracia. Entretanto, não é aí que se deve procurar a força motriz desta arte: no contato dela com o povo, o qual vinha participar das 'festas religiosas dos templos e monasteiros. As representações de sarugaku ali realizadas, no início, eram executadas pelos funcionários dos estabelecimentos religiosos; mas com a aparição dos atores profissionais surgidos do povo, os primeiros vão lhes cedendo seus lugares progressivamente. A aparição dos profissionais, sem sombra de dúvida, constitui uma prova do sucesso que essa arte desfrutava na época. Vale dizer que a arte de dengaku vivia o mesmo processo de evolução que o sarugaku, desde o século XI.

Quem eram então esses atores do sarugaku? Muitos deles eram aqueles que fizeram da sua habilidade a sua profissão, mas também havia os que já eram tradicionalmente artistas de sangaku. Imagina-se que, após esses últimos terem perdido a proteção e o apoio oficial, isto é, a partir da abolição do sangakko, em 782, por motivo ainda hoje ignorado, esses artistas haviam retornado ao povo e se tornado profissionais, com o objetivo de perpetuar a sua arte, transformando-a em meio de vida. Como eles eram geralmente estrangeiros naturalizados, vindos do continente, era fácil manter a tradição do sarugaku em seu meio. Foi, talvez, respaldado por esta tradição que, mais tarde, Zeami considerou como o ancestral longínquo do sarugaku da província de Yamato, o personagem Hada no Kôkatsu - considerado como uma reencarnação do primeiro soberano do Grande Império Ts'in, fundador desta dinastia (221206 a.C.).

De qualquer forma, esses atores foram organizando as suas companhias, em torno dos templos e monasteiros de expressão que lhes davam apoio. As companhias, por sua vez, com a obtenção deste apoio, tinham a obrigação de participar dos serviços religiosos dos estabelecimentos a que se viam ligados, através de representações de sarugaku, nas festividades religiosas.

Zeami explica, no livro IV de Fûshikaden "Da transmissão da flor de interpretação", que as quatro companhias de sarugaku ligadas a esses serviços religiosos obrigatórios do templo Kasuga, na província de Yamato eram: Tobi, Yûzaki, Sakado e Enmai. Essas companhias, denominadas sarugaku de Yamato, foram precursoras de Hôshô, Kanze, Kongô e Konparu, respectivamente Constituíam as quatro das cinco escolas de nô que se encontram ainda hoje, em plena atividade. A quinta escola é Kita, fundada numa época posterior à de Zeami, no período Azuchi Momoyama, entre 1576-1600. 
Ainda através de dados contidos em Fûshikaden, sabemos que as três companhias que participavam dos serviços religiosos do templo Hie eram Yamashina, Shimosaka e Hie, os quais formavam o sarugaku da região de Ômi.

Além disso, outros tratados de Zeami nos informam da existência de diversas companhias de sarugaku, espalhadas nas regiões próximas a Kyôto e mesmo em outras províncias. Documentos guardados nos templos e monasteiros nos dão conta da existência de companhias como as das regiões de Ochi ou de Daikô. Entretanto, não nos parece necessário prosseguir, aqui, na sua enumeração. $O$ que nos interessa saber é que no século XIV havia um grande número de companhias de sarugaku espalhadas em várias regiões do Japão.

Outro fato que podemos destacar são os nomes atribuídos a essas companhias, pois eram, originalmente, aqueles das localidades de suas fundações ou então dos templos e monasteiros de que dependiam. Posteriormente, foram substituídos por nome de atores que se tornaram célebres na companhia. Assim, por exemplo, as companhias Tobi e Sakado, citadas no Fûshikaden, aparecem algumas décadas mais tarde, no tratado Zeshi rokujû igo sarugaku dangi, "Considerações sobre sarugaku com Zeshi, após seus sessenta anos", com os nomes de seus líderes Hôshô e Kongô, respectivamente, o que prova a independência maior adquirida por essas companhias.

Por outro lado, não podemos esquecer que esses templos e monasteiros eram administrados pelos proprietários de terra e por administradores regionais que poderiam ser monges mas também guerreiros. Eles se ocupavam das atividades culturais de seus templos e monasteiros. Bastante baixo no início, o nível dessas manifestações vai se elevando com o passar dos anos, à medida que a cultura da capital ganhava as províncias. Essa penetração se deu graças aos guerreiros vassalos, administradores das províncias. Na época Kamakura, esses vassalos, que possuíam suas residências principais nas províncias de sua administração, tinham a importante obrigação de assegurar a ordem em Kyôto em épocas de paz. Essa obrigação que os retinha na capital por um tempo determinado durante o ano, permitia-lhes um contato constante com a cultura refinada que aguçava as suas sensibilidades artísticas. Assim, esses guerreiros que eram organizadores das festividades dos templos e monasteiros e, também os seus principais espectadores, exigiam, com seu gosto artístico desenvolvido, representações que já esboçassem uma certa linha narrativa. Desta forma, mesmo nas províncias, as bases para o desenvolvimento do sarugaku já haviam sido formadas, e ainda, na medida em que a economia baseada em moedas se expandia, nas diversas regiões o nível de vida da população se elevava, permitindo-lhe um acesso maior a uma vida cultural mais rica.

Finalmente, o apoio da classe superior guerreira à arte de dengaku foi muito importante no processo de formação do nô. A fascinação do regente 
Hôjô Takatoki (1303-1333) por dengaku é célebre, citada mesmo no Taihei$k i$ "Crônica da grande paz" - narrativa histórico-militar considerada de autoria do monge Kojima. Os grafites do leito seco do rio Nijô apontam esse fato como indício da decadência do governo militar da época Kamakura.

Entretanto, a paixão de Takatoki por dengaku estava profundamente enraizada no gosto da época. E por isso que o dengaku, apesar de todas as críticas adversas, continuou sendo apreciado no meio militar, mesmo durante o predomínio dos primeiros xogun Ashikaga.

E essa florescente arte de dengaku criou um terreno extremamente propício ao nascimento do teatro nô. A aparição dos dois homens de talento no sarugaku da região de Yamato, Kan'ami e Zeami, que receberam fortes influências de dengaku, e as suas ligações posteriores com o xogun Ashikaga Yoshimitsu constituíram acontecimentos decisivos para a eclosão da "flor de nô"

Veremos, a seguir, a participação desses personagens que, com todo seu peso, contribuíram para a formação do teatro nô.

Dentre as diversas companhias de sarugaku, aquelas da região de Ómi e as de Yamato eram as mais conhecidas por causa de suas comprovadas capacidades artísticas. O chefe da companhia Hie, da região de Ómi, Inuô Dôa - foi considerado por Zeami como um dos mestres da sua arte.

Entretanto, foi Kanze Kiyotsugu (1333-1384), mais conhecido como Kan'ami, da companhia Yûzaki da região de Yamato, o primeiro a elevar a arte de sarugaku à posição de maior destaque dentre todas as outras artes de representação, obtendo o apoio e a proteção do xogun da época, Ashikaga Yoshimitsu, através da sua habilidade artística. Tal foi a importância deste artista para a arte de sarugaku, que Inuô Dôa, da região de Ômi fazia celebrar, todo dia 19 do mês, dia da morte de Kan'ami, uma cerimônia religiosa em sua memória para the agradecer o sucesso que trouxera à arte de sarugaku. Zeami narra esse fato no capítulo XXI do tratado Żeshi rokujû igo saruku dangi.

Todavia, apesar da importância desse personagem, não nos restam muitas informações sobre a sua vida, salvo aquelas concernentes ao seu trabalho, que constam principalmente do tratado acima referido e também do Fûshikaden.

Como ator, o elogio maior que recebeu Kan'ami foi o de ser considerado o único que agradava, da mesma forma, aos nobres e aos poderosos, assim como ao povo das províncias mais longínquas, das montanhas mais recuadas. Ele modulava a sua arte segundo a disposição de espírito daqueles que o assistiam, levando em conta os usos e os costumes do lugar.

Como autor, Kan'ami contribuiu para o enriquecimento do repertório do sarugaku, escrevendo novas peças e também readaptando as velhas. Sotoba 
Komachi, Jinen Koji, ou Matsukaze são peças famosas de sua autoria que continuam a ser representadas nos palcos atuais. Embora saibamos que essas peças tenham chegado até nós sofrendo retoques e adaptações, podemos nelas perceber certos elementos que podem satisfazer um público amplo. Os personagens a quem Kan'ami dava vida não eram aqueles extraídos da literatura clássica mas os da tradição oral, mais próximos ao povo.

Como compositor, Kan'ami inovou a música do sarugaku. As modificações radicais que introduziu no canto do sarugaku tornaram-se um dos pontos fortes de sua arte para vencer os inúmeros rivais da época. Ele introduziu na música, o kouta do canto do sarugaku, a música de kusemai, muito em voga na época, misturando na característica melodiosa do primeiro, os efeitos rítmicos do segundo. Além disso, a introdução do kusemai nas peças de sarugaku, posteriormente, inspirou Zeami a criar suas peças com novas estruturas de composição. Kan'ami utilizou as qualidades narrativas do canto de kusemai para expor o tema no meio da peça, compondo, desta forma, a estrutura do "nô de aparição" Como se vê,, Kan'ami preparou um terreno extremamente propício para Zeami aperfeiçoar a arte do sarugaku, que hoje conhecemos com o nome de nô.

Kan'ami morreu em 1384, com 52 anos, na província de Suruga, onde fazia uma tournée. Sua última representação foi, segundo Zeami, a "eclosão de uma flor sobre o galho de uma árvore velha e seca com folhas esparsas"

A arte de sarugaku, todavia, foi aceito pelos poderosos guerreiros e por todas as classes privilegiadas da sociedade, apenas a partir do momento em que passou a contar com o apoio de um homem extremamente poderoso, o xogun Ashikaga Yoshimitsu.

Esse xogun que, como os seus predecessores Takauji ou Yoshiakira, apreciava o dengaku, passou a preferir o sarugaku quando assistiu pela primeira vez, ao seu espetáculo por ocasião das cerimônias religiosas do templo Imagumano, em Kyôto. Kan'ami, que era o chefe desta companhia, se encontrava no apogeu da sua arte com seus 40 anos. Zeami, seu herdeiro, tinha, na ocasião, apenas 12 anos. A peça Okina, a primeira deste dia, foi representada por Kan'ami, fato que veio a romper toda uma tradição teatral que envolvia esta peça. Okina era considerada uma peça sagrada e, até aquela data, era representada pelo mais velho ancião da companhia. Ter um xogun como espectador era uma oportunidade máxima para companhia Yûzaki: nenhum erro poderia ser cometido. A companhia tinha todo o interesse em cativar Yoshimitsu para a arte, desde o início do espetáculo.

Impressionado com a arte de Kan'ami, Yoshimitsu, de imediato, se apaixonou por sarugaku, ao mesmo tempo em que se sentiu profundamente 
atraído pela beleza de Zeami. Documentos da época nos contam que Zeami tinha uma elegância e uma beleza extremamente refinada.

Vários são também os documentos que falam da ligação de Yoshimitsu com Zeami: Gokumai-ki "Crônica das estupidezas", de autoria do ministro. Sanjô Kimitada, Kûge rôshi nichiyô kufû ryaku-shû "Coleção concisa das idéias cotidianas do velho mestre Kûge", do bonzo Gidô Shûshi, entre outros.

Todos eles criticam o envolvimento de Yoshimitsu com o sarugaku e com Zeami, ora porque o xogun levava, em sua companhia, esse menino a locais públicos, o que não deveria ser uma atitude digna de um homem de sua classe, ora porque o envolvimento com uma arte de diversão como o saruga$k u$ constituía sempre um obstáculo para a arte de bem governar.

Todavia, Yoshimitsu, homem de forte personalidade, não se deixou impressionar pelas críticas e continuou a proteger o sarugaku até o fim de sua vida, incentivando-o a prosseguir no aprimoramento da sua arte. Com efeito, Yoshimitsu sempre se mostrou um crítico muito severo da sua arte preferida, como contam várias passagens de Zeshi rokujû igo sarugaku dangi.

Para finalizar, faremos algumas considerações sobre Zeami, aquele que concluiu o aperfeiçoamento do sarugayu.

Zeami, filho de Kan'ami, igulamente artista de sarugaku, nasceu em 1363, numa época em que o governo Ashikaga mostrava os primeiros sinais de consolidação no poder. Era também uma época de grande fertilidade para todas as artes. No que tange às artes de representação, o sarugaku e o dengaku disputavam entre si a posição de maior destaque entre todas. As companhias de sarugaku se multiplicavam em todas as regiões do Japão e as de dengaku, apesar de serem apenas duas, uma na região de Yamato e outra nos arredores de Kyôto, encontravam-se em pleno apogeu. Portanto, Zeami nasceu numa época em que se exigia de um artista, um imenso esforço já para se afirmar como tal e ainda mais para manter uma companhia teatral de destaque. Zeami era o herdeiro da companhia Yûzaki, chefiada por seu pai.

$\mathrm{O}$ encontro com a xogun Yoshimitsu, aos 12 anos, provocou uma mudança radical em sua vida. Com efeito, a partir desse momento, toda a cultura tradicional e aristocrática de Kyôto encontrava-se à sua disposição, exercendo uma influência decisiva sobre sua formação e sobre sua arte. Por outro lado, as passagens de Zeshi rokujû igo sarugaki dangi contam a sensibilidade aguçada desse menino que, aos doze anos, já possuía um profundo espírito crítico para sentir e avaliar as representações de altos níveis artísticos.

O seu encontro, aos treze anos, com Nijô Yoshimoto - intelectual e poeta de primeira grandeza da aristocracia do norte, também marcou fortemente a formação literária de Zeami. 
Aos 22 anos, com a morte súbita do pai e mestre Kan'ami, Zeami se encontra frente às responsabilidades imensas de sustentar a renomada companhia Yûzaki e de manter a liderança dela entre as outras, quando a sua arte ainda não havia se firmado totalmente. Quatro anos mais tarde, desaparece Nijô Yoshimoto, aquele que tão bem tinha-lhe ensinado a arte de poetar. Com a morte de Yoshimitsu em 1408, Zeami perdia o seu protetor incondicional, aquele que o apoiava desde os seus 12 anos.

O xogun Ashikaga Yoshimochi, sucessor de Yoshimitsu, preferiu como o seu avô Yoshiakira, a arte de dengaku. Nesta arte, o seu protegido era Zôami, um artista com grandes qualidades e um grande rival de Zeami. Entre os dois rivais sempre houve mútuo respeito e apreciação. Nada prova que Yoshimochi, embora tendo preferência por Zôami, tenha tentado prejudicar Zeami de forma deliberada. Mesmo durante o período de reaparecimento do dengaku, Zeami continuou exercendo intensamente suas atividades teatrais, não nos palcos, mas escrevendo inúmeras peças e tratados teóricos. Foi de 1403 até 1428, ano da morte de Yoshimochi, que Zeami escreveu 13 dos seus 19 tratados.

A verdadeira dificuldade para Zeami começa, quando, após a morte de Yoshimochi, sobe ao poder Ashikaga Yoshinori, um grande apaixonado do sarugaku, que protegia Motoshige On'ami, sobrinho de Zeami. A companhia Kanze, antiga Yûzaki, chefiada por Motomasa, filho mais velho de Zeami, foi reduzida praticamente ao nada, em Kyôto, por causa da perseguição ferrenha da Yoshinori. Após a morte de Motomasa, durante uma tournée pela província de Ise, Motoshige On'ami passa a ser o chefe oficial da companhia Kanze, apesar da contrariedade de Zeami. Este nunca chegou a aceitar esse novo chefe.

Em 1434, Zeami é exilado na ilha de Sado por ordem de Yoshinori. Não se sabe ao certo o motivo dessa punição. Alguns pesquisadores acreditam que foi por Zeami ter se negado a mostrar a Motoshige On'ami os seus tratados teatrais. Mas mesmo no exílio, Zeami não abandonou a arte de sarugaku e continuou orientando Zenchiku nesta arte, através de cartas. Zenchiku era o chefe da companhia Konparu de sarugaku, da província de Yamato e genro de Zeami.

Depois desse exílio, nada nos resta sobre a vida de Zeami, nem mesmo se ele pôde retornar a Kyôto. Pelos documentos da época sabe-se apenas que deve ter falecido provavelmente aos 81 anos, no oitavo dia do oitavo mês.

Zeami foi um autor notável de peças de nô. Cerca de cinqüenta peças são hoje consideradas como sendo de sua autoria, incluindo-se aquelas perdidas e também obsoletas. 
Pela análise de suas peças, percebe-se que o shite, personagem principal, é geralmente um espírito, uma divindade ou um fantasma - enfim, aquele que não pertence ao mundo dos vivos. Essas peças possuem uma estrutura especialmente elaborada, com o objetivo de colocar em cena essas aparições. Por oposição às "peças de realidade", onde a ação se desenvolve paralelamente a uma ordem cronológica, com bases no antagonismo entre personagens reais e irreais, os acontecimentos do "nô de aparição" não seguem nenhuma ordem cronológica, sendo que o tempo da segunda parte da peça retrocede em relação à primeira, como se uma cena de recordação interferisse no momento presente. Zeami, nas suas peças não conta os feitos do shite que representa geralmente o fantasma de renomados personagens históricos, mas os sentimentos e emoções desses heróis ou heroínas, que são idênticos aos de qualquer outro ser humano. O "nô de aparição" de Zeami procura descrever a alma do herói, dentro de uma atmosfera sutil que fica entre o sonho e a realidade.

Zeami nos deixou também 21 transmissões. Dentre elas, 19 são tratados teatrais, 1 é uma lamentação da morte de seu filho Motomasa e a última, uma obra poética que conta seu exílio na ilha de Sado. Além dessas transmissões restam-nos apenas duas cartas que Zeami enviou do exílio, para Zenchiku.

Os escritos teóricos de Zeami, ou melhor, os tratados teatrais, eram obras para serem transmitidas secretamente a um só homem capaz por geração, o qual garantiria a longevidade da arte do sarugaku. Mesmo sendo um grande mestre, dizia Zeami, se não conseguir criar um sucessor, a sua arte desaparecerá após seu curto tempo de existência.

Embora Zeami tivesse conhecido, no final da sua vida, um momento nefasto, a arte a que se dedicou durante toda a sua existência continua viva, como ele desejava, sendo representada em diversos palcos do Japão moderno, com um público cada vez maior. Atores do nô mais jovens, procuram novos caminhos para este teatro, preservando o ensinamento de Zeami, segundo o qual, uma arte deve corresponder sempre ao gosto da época.

Por outro lado, os ensinamentos de Zeami tomaram outros caminhos nem mesmo imaginados por ele próprio. Influenciaram e influenciam os teóricos ocidentais de teatro, ultrapassando mesmo as fronteiras do Japão. Isto se deve ao fato de que, embora Zeami tivesse exposto suas idéias de uma forma particular, os seus conteúdos são universais, pois falam da verdadeira natureza da arte teatral, do qual os homens de teatro devem estar conscientes.

(Este trabalho foi apresentado em forma de conferência, no ciclo "Aspectos da Cultura Japonesa", realizada no dia 25 de setembro de 1987, no Centro de Estudos Japoneses) 